\title{
PELAKSANAAN EKSTRAKURIKULER PENDIDIKAN AGAMA ISLAM DI SEKOLAH: Studi di SMPN 3 Malang Tahun 2018
}

\author{
Rizki Susanto dan Utien Kustianing \\ IAIN Pontianak dan SMPN 3 Malang, Indonesia \\ Rizkisusanto.pai@gmail.com
}

\begin{abstract}
Islamic Education in school is an education that provides knowledge, skill, and develops students' attitude so they can practice Islamic teachings with properly. Implementation of Islamic Education in reality is not enough only with lessons Islamic Education but must to developed through extracurricular Islamic Education. This writing focussed is to description extracurricular Islamic Education in State Junior High School 3 Malang. The question who wants to be answered is form and implementations extracurricular Islamic Education in State Junior High School 3 Malang in years 2018. Extracurricular Islamic Education at State Junior High School 3 Malang covering: 1) Imtaq, 2) dhuhur and Jumah together, 3) coaching female students, 4) Islamic preaching council, 5) Qur'an read program, 6) Quran tahfidz program, 7) charity program, 8) commemoration of Islamic days, 9) Qur'an tahseen program, and 10) Ramadhan activities.
\end{abstract}

Keywords: Extracurricular, Islamic Education and State Junior High School 3 Malang

\begin{abstract}
Abstrak: Pendidikan Agama Islam pada sekolah merupakan pendidikan yang memberikan pengetahuan, keterampilan, dan membentuk sikap siswa sehingga mereka dapat mengamalkan ajaran Islam dengan benar. Pelaksanaan PAI pada kenyataanya tidak cukup hanya dengan mata pelajaran PAI namun harus dikembangkan melalui ekstrakurikuler PAI. Fokus tulisan ini adalah untuk mendeskripsikan kegiatan ekstrakurikuler PAI di SMPN 3 Malang. Pertanyaan yang ingin dijawab yaitu bentuk dan pelaksanaan ekstrakurikuler PAI di SMPN 3 Malang tahun 2018. Adapun ekstrakurikuler PAI yang dilaksanakan di SMPN 3 Malang tahun 2018 terdiri dari: (1) Imtaq, (2) Dzuhur dan Jum'at berjamaah, (3) pembinaan keputrian, (4) Badan Dakwah Islam, (5) program baca Al-Qur'an, (6) program tahfidz Qur'an, (7) program amal, (8) Peringatan Hari Besar Islam, (9) program tahsin Qur'an, dan (10) kegiatan Ramadhan.
\end{abstract}

Kata Kunci: Ekstrakurikuler, Pendidikan Agama Islam dan SMPN 3 Malang

\section{A. Pendahuluan}

Pendidikan agama merupakan pilar utama dalam upaya mencetak generasi bangsa Indonesia yang beriman, bertakwa dan berakhlakul karimah sehingga perlu ada suatu sistem yang mengatur pola pendidikan agama yang sesuai bagi masyarakat, khususnya rakyat Indonesia. Dalam UUD 1945 dijelaskan bahwa pemerintah Republik Indonesia mengusahakan dan menyelenggarakan satu sistem 
pendidikan nasional, yang meningkatkan keimanan dan ketakwaan serta ahlak mulia dalam rangka mencerdaskan kehidupan bangsa, yang diatur dalam undangundang ${ }^{97}$.

Dalam undang-undang SISDIKNAS, Pendidikan Nasional diartikan sebagai pendidikan yang berdasarkan Pancasila dan Undang-Undang Dasar Negara Republik Indonesia Tahun 1945 yang berakar pada nilai-nilai agama, kebudayaan nasional Indonesia dan tanggap terhadap tuntutan perubahan zaman ${ }^{98}$. Oleh karena itu, sudah sewajarnya pendidikan agama menjadi pilar utama dalam mencerdaskan kehidupan bangsa melalui sistem pendidikan di Indonesia. Pendidikan agama sendiri telah ditetapkan menjadi mata pelajaran wajib di semua jenjang pendidikan mulai dari sekolah dasar hingga perguruan tinggi sesuai ketetapan MPRS No. XXVII/MPRS/1966 tentang Agama, Pendidikan dan Kebudayaan, sebagai berikut:

Mengubah diktum Ketetapan MPRS No. II/MPRS/1960 Bab II Pasal 2 ayat (3), dengan menghapuskan kata "... dengan pengertian bahwa murid-murid berhak tidak ikut serta, apabila wali murid/murid dewasa menyatakan keberatannya ...." sehingga kalimatnya berbunyi sebagai berikut "Menetapkan pendidikan agama menjadi mata pelajaran di sekolah-sekolah mulai dari sekolah dasar sampai dengan universitas-universitas negeri" ${ }^{199}$.

Ketetapan tersebut mengukuhkan kedudukan pendidikan agama sebagai tonggak utama dalam upaya pembentukan jati diri rakyat Indonesia yang agamis berasaskan pancasila. Dalam Peraturan Pemerintah No. 55 Tahun 2007 tentang Pendidikan Agama dan Pendidikan Keagamaan dijelaskan bahwa:

Pendidikan agama adalah pendidikan yang memberikan pengetahuan dan membentuk sikap, kepribadian, dan keterampilan peserta didik dalam mengamalkan ajaran agamanya, yang dilaksanakan sekurang-kurangnya melalui mata pelajaran/kuliah pada semua jalur, jenjang, dan jenis pendidikan ${ }^{100}$.

Kata "sekurang-kurangnya" mengidentifikasi bahwa saat ini pendidikan agama yang ada di sekolah masih menjadi mata pelajaran semata, padahal dalam pembentukan kepribadian, keterampilan, dan sikap peserta didik diperlukan

97 Pasal 31 Ayat 3 Undang-Undang Dasar NRI 1945.

98 Pasal 1 Ayat 2 Undang-Undang Nomor 20 Tahun 2003 tentang Sistem Pendidikan Nasional.

${ }_{99}$ Pasal 1 Ketetapan No. XXVII/MPRS/1966 tentang Agama, Pendidikan dan Kebudayaan.

100 Pasal 1 Ayat 1 Peraturan Pemerintah Nomor 55 Tahun 2007 tentang Pendidikan Agama dan Pendidikan Keagamaan. 
kegiatan-kegiatan penunjang di luar mata pelajaran di sekolah yakni melalui kegiatan ekstrakurikuler pendidikan agama.

Hal tersebut sebagaimana dijelaskan dalam Peraturan Menteri Agama (PMA) No. 16 Tahun 2010 tentang Pengelolaan Pendidikan Agama pada Sekolah, sebagai berikut. Pertama, proses pembelajaran pendidikan agama dilakukan dengan mengedepankan keteladanan dan pembiasaan akhlak mulia serta pengamalan ajaran agama. Kedua, proses pembelajaran pendidikan agama dikembangkan dengan memanfaatkan berbagai sumber dan media belajar yang dapat mendorong pencapaian tujuan pendidikan agama. Ketiga, proses pembelajaran pendidikan agama dilakukan melalui kegiatan intrakurikuler dan ekstrakurikuler ${ }^{101}$.

Berdasarkan penjelasan di atas, dapat kita ketahui bahwa pendidikan agama di sekolah seharusnya dapat dilaksanakan dalam berbagai aktivitas pembelajaran baik di dalam kelas melalui mata pelajaran maupun di luar kelas melalui kegiatan ektrakurikuler agar dapat mengoptimalkan proses pendidikan agama bagi peserta didik dan akhirnya dapat meningkatkan keberhasilan dalam proses belajar mengajar pendidikan agama di sekolah.

Sekolah Menengah Pertama Negeri 3 Malang adalah sekolah yang memiliki beragam kegiatan ekstrakurikuler PAI sebagai penunjang mata pelajaran PAI. SMPN 3 Malang sendiri merupakan sekolah bersertifikat ISO 9001 tahun 2008 dan IWA 2 tahun 2012, dengan visinya yaitu “Unggul dalam IPTEKS, Terampil dan Mandiri berlandaskan IMTAQ, Berbudi Pekerti Luhur, dan Melestarikan Lingkungan". SMPN 3 Malang yang beralamat di Jl. Dr. Cipto No. 20 Malang adalah sekolah dengan banyak prestasi, baik di bidang akademik dan non-akademik ${ }^{102}$.

Tulisan ini berfokus pada kegiatan ekstrakurikuler PAI di SMPN 3 Malang dengan pertanyaan yang ingin dijawab berupa bentuk dan pelaksanaan kegiatan ekstrakurikuler PAI di SMPN 3 Malang tahun 2018. Metode yang digunakan adalah metode kualitatif deskriptif untuk menggambarkan secara menyeluruh tentang pelaksanaan kegiatan ekstrakurikuler PAI di SMPN 3 Malang tahun 2018.

101 Pasal 8 Ayat 1-3 Peraturan Menteri Agama Nomor 16 Tahun 2010 tentang Pengelolaan Pendidikan Agama pada Sekolah.

102 Profil SMPN 3 Malang, URL: http:/ / smpn3-mlg.sch.id/, diakses pada 11 Januari 2019. 


\section{B. Ekstrakurikuler Pendidikan Agama Islam}

Pengertian Pendidikan Agama Islam yang digunakan pada tulisan ini menggunakan dua pengertian berikut. Pertama, PAI adalah upaya mendidik agama Islam atau ajaran Islam dan nilai-nilainya agar menjadi way of life (pandangan dan sikap hidup) seseorang ${ }^{103}$. Kedua, PAI adalah usaha sadar yang dilakukan pendidik dalam mempersiapkan peserta didik untuk meyakini, memahami, dan mengamalkan ajaran Islam melalui kegiatan bimbingan, pengajaran atau pelatihan yang telah direncanakan untuk mencapai tujuan yang telah ditetapkan ${ }^{104}$. Sehingga makna PAI bukan disematkan pada nama mata pelajaran semata, namun memiliki pengertian yang lebih luas. Suradi menerangkan bahwa PAI tidak hanya mengantarkan manusia untuk menguasai ajaran Islam, tetapi yang terpenting adalah bagaimana manusia dapat mengamalkan ajaran-ajaran Islam dalam kehidupan sehari-hari ${ }^{105}$.

Pengertian ekstrakurikuler PAI dijelaskan dalam Peraturan Direktur Jenderal Pendidikan Islam No. Dj.I/12A Tahun 2009 tentang Penyelenggaraan Kegiatan Ekstrakurikuler PAI pada Sekolah, sebagai berikut:

Ekstrakurikuler PAI adalah upaya pemantapan, pengayaan, dan perbaikan nilai-nilai, norma serta pengembangan bakat, minat, dan kepribadian peserta didik dalam aspek pengalaman dan penguasaan kitab suci, keimanan, ketakwaan, akhlak mulia, ibadah, sejarah, seni dan kebudayaan, dilakukan di luar jam intrakurikuler, melalui bimbingan guru PAI, guru mata pelajaran lain, tenaga kependidikan dan tenaga lainnya yang berkompeten, dilaksanakan di sekolah atau di luar sekolah ${ }^{106}$.

Dalam hal ini, perlu digarisbawahi bahwa ekstrakurikuler PAI tidak semata tanggung jawab guru PAI, karena pembinaan pendidikan agama peserta didik di sekolah merupakan tanggung jawab seluruh pendidik dan tenaga kependidikan di sekolah. oleh karena itu, dibutuhkan peran aktif dari seluruh civitas akademik untuk mensukseskan ekstrakurikuler PAI tersebut.

103 Muhaimin, Pengembangan Kurikulum Pendidikan Agama Islam di Sekolah, Madrasah, dan Perguruan Tinggi, (Jakarta: Rajawali Pers, 2009), hlm. 7-8.

104 Abdul Majid, Belajar dan Pembelajaran Pendidikan Agama Islam, (Bandung: Remaja Rosdakarya, 2014), hlm. 13.

${ }^{105}$ A. Suradi, “Globalisasi dan Respon Pendidikan Agama Islam di Sekolah" dalam Jurnal Mudarrisuna, Vol. 7, No. 2, 2017, hlm. 264-265.

106 Peraturan Direktur Jenderal Pendidikan Islam No. Dj.I/12A Tahun 2009 tentang Penyelenggaraan Ekstrakurikuler PAI pada Sekolah. 
Dalam pedoman ekstrakurikuler PAI dijelaskan fungsi dan tujuan dari ekstrakurikuler PAI. Adapun fungsinya yaitu:

1. Pembinaan, yaitu membentuk perilaku Islami dalam kehidupan sehari-hari dan memberikan bantuan klinis bagi peserta didik yang mengalami kesulitan dalam penguasaan kompetensi PAI;

2. Pengembangan, yaitu bahwa kegiatan ekstrakurikuler berfungsi untuk mendukung perkembangan personal peserta didik melalui perluasan bakat, minat, dan kreativitas;

3. Sosial, yaitu bahwa kegiatan ekstrakurikuler berfungsi untuk mengembangkan kemampuan dan tanggung jawab sosial keagamaan peserta didik. Kompetensi sosial dikembangkan dengan memberikan kesempatan kepada peserta didik untuk memperluas pengalaman, praktik keterampilan sosial, dan internalisasi nilai moral dan nilai sosial keagamaan;

4. Rekreatif, yaitu bahwa kegiatan ekstrakurikuler dilakukan dalam suasana rileks, menggembirakan, dan menyenangkan sehingga menunjang proses perkembangan peserta didik. Kegiatan ekstrakurikuler harus mengembangkan kehidupan budaya Islami di sekolah yang lebih menarik bagi peserta didik;

5. Persiapan karir, yaitu untuk mengembangkan kesiapan karir peserta didik melalui pengembangan kapasitas dan kompetensi PAI.

Sementara itu, tujuan dari ekstrakurikuler PAI dapat penulis jelaskan sebagai berikut:

1. Meningkatkan kemampuan sikap, pengetahuan, dan keterampilan peserta didik;

2. Mengembangkan bakat dan minat peserta didik dalam pembina-an kepribadian muslim;

3. Mewujudkan budaya keberagamaan (religious culture) pada tingkat satuan pendidikan;

4. Meningkatkan syi'ar Islam ${ }^{107}$.

107 Direktorat Pendidikan Agama Islam, Pedoman Ekstrakurikuler PAI SMP, (Jakarta: Kemenag, 2015), hlm. 3. 
Adapun bentuk-bentuk kegiatan ekstrakurikuler PAI yang disebut dalam buku panduan penyelenggaraan ekstrakurikuler PAI pada SMP, antara lain:

1. Pesantren Kilat;

2. Pembiasaan Ahklak Mulia;

3. Tuntas Baca Tulis Al-Qur'an;

4. Ibadah Ramadhan;

5. Wisata Rohani;

6. Kegiatan Rohani Islam;

7. Pekan Keterampilan dan Seni PAI;

8. Peringatan Hari Besar Islam ${ }^{108}$.

Sementara dalam pedoman lainnya disebutkan jenis-jenis kegiatan ekstrakurikuler PAI, sebagai berikut:

1. Baca Tulis al-Quran (BTQ);

2. Tahfizh al-Quran;

3. Pembinaan Tilawah al-Quran;

4. Seni Kaligrafi;

5. Ceramah Keagamaan (muhadharah);

6. Nasyid;

7. Seni musik Islami (rebana, marawis, samroh, hadroh, qasidah dan sejenisnya);

8. Jurnalistik Islam (majalah dinding, bulletin, leaflate, jurnal, poster, karikatur, blog, website, dan lain-lain) ${ }^{109}$.

Dalam merencanakan kegiatan ekstrakurikuler pendidikan agama Islam, sekolah dapat menyesuaikan bentuk atau jenis kegiatan sesuai dengan potensi daerah masing-masing. Hal ini sebagaimana dijelaskan sebagai berikut:

Sekolah dapat mengembangkan dan menambah kegiatan ekstrakurikuler pendidikan agama sesuai dengan kemampuan dan kebutuhan. Pengembangan kegiatan ekstrakulikuler Pendidikan Agama harus selaras dengan tujuan Pendidikan nasional dan memperkokoh kesatuan dan persatuan bangsa110.

108 Kementerian Agama RI, Panduan Umum Penyelenggaraan Kegiatan Ekstrakurikuler Pendidikan Agama Islam Sekolah Menengah Pertama, (Jakarta: Direktorat Pendidikan Agama Islam, 2012), hlm. 3238.

109 Direktorat Pendidikan Agama Islam, Pedoman Ekstrakurikuler......, hlm. 4.

110 Pasal 13 Ayat 1-3 Peraturan Menteri Agama Nomor 16 Tahun 2010 tentang Pengelolaan Pendidikan Agama pada Sekolah. 
Pelaksanaan kegiatan ekstakurikuler pendidikan agama di sekolah sendiri memiliki dampak terhadap pembinaan akhlak peserta didik sebagaimana diungkapkan oleh Said, bahwa:

Dampak ekstrakurikuler dalam pembinaan akhlak peserta didik diantaranya adalah antusias peserta didik dalam mengikuti kegiatan ekstrakurikuler keagamaan cukup bagus karena peserta didik mengikuti kegiatan ekstrakurikuler atas kemauan sendiri, peserta didik lebih disiplin dalam melaksanakan salat berjamaah, dan tumbuhnya kepekaan sosial terhadap sesama manusia ${ }^{111}$.

Dalam upaya mengoptimalkan pendidikan agama Islam di sekolah diperlukan upaya peningkatan mutu pendidikan itu sendiri. Menurut Manizar terdapat 5 langkah yang diperlukan dalam upaya tersebut yaitu:

1. Adanya kesetaraan sejawat di sekolah;

2. Sarana penunjang kegiatan;

3. Dukungan pihak terkait;

4. Menerapkan pengintegrasian PAI;

5. Melakukan evaluasi112.

\section{Ekstrakurikuler PAI di SMPN 3 Malang}

Kegiatan ekstrakurikuler PAI yang dilaksanakan di SMPN 3 Malang terdiri dari 10 kegiatan yaitu: 1) Imtaq, 2) Dzuhur dan Jum'at berjamaah, 3) pembinaan keputrian, 4) Badan Dakwah Islam, 5) program baca Al-Qur'an, 6) program tahfidz Qur'an, 7) program amal, 8) Peringatan Hari Besar Islam, 9) program tahsin Qur'an, dan 10) kegiatan Ramadhan.

\section{Imtaq}

Kegiatan Imtaq dilaksanakan setiap Selasa sampai Kamis pukul 06.30-07.00 wib. Kegiatan Imtaq dimulai oleh guru PAI dengan mengucap salam dan membaca surah Al-Fatihah, dilanjutkan pembacaan asmaul husna dan Qur'an bersama-sama di bantu alat pengeras suara selama \pm 15 menit, dan kegiatan

111 Said, “Dampak Kegiatan Ekstrakurikuler Pendidikan agama Islam dalam Pembinaan Akhlak Peserta Didik di SMK Negeri 2 Raha”, Tesis tidak diterbitkan, UIN Alauddin Makassar, 2012, hlm. 113.

112 Manizar, E., “Optimalisasi Pendidikan Agama Islam di Sekolah”, dalam Jurnal Tadrib, Vol. 3, No. 2, Februari 2018, hlm. 251. 
diakhiri dengan doa meminta keselamatan dunia dan akhirat, kebaikan ibu dan bapak, dan memohon ilmu dan kepahaman. Khusus hari kamis ditambah dengan istiqhosah. Kegiatan Imtaq dilaksanakan di halaman sekolah dengan melibatkan seluruh siswa SMPN 3 Malang dan dewan guru yang ikut berpartisipasi dengan mengawasi siswa.

Imtaq merupakan kegiatan yang dapat diimplementasikan pada tingkat SMP/sederajat maupun SMA/sederajat dengan menyesuaikan kebutuhan sekolah berdasarkan keunggulan dan potensi yang dimiliki daerah masing-masing. Dampak positif Imtaq, antara lain: meningkatkan keimanan melalui pembacaan asmaul husna, menumbuhkan kesadaran beragama melalui pembacaan AlQur'an, dan menguatkan mental siswa melalui istighosah dan do'a.

\section{Dzuhur dan Jum'at Berjamaah}

Shalat dzuhur dan Jum'at berjamaah dilakukan di Masjid Bintaraloka yang dimiliki oleh SMPN 3 Malang. Kegiatan ini merupakan bagian dari pembinaan shalat berjamaah yang dilakukan secara bersama-sama guru dan siswa di Masjid Bintaraloka. Dalam pelaksanaan shalat Jum'at, guru PAI telah menyusun jadwal petugas shalat Jum'at dan materi khutbah telah disesuaikan dengan kebutuhan peserta didik.

Kegiatan shalat berjamaah bertujuan membiasakan siswa melaksanakan shalat secara rutin dengan harapan siswa dapat melaksanakan shalat lima waktu dengan baik dan benar. Oleh karena itu, guru harus berperan aktif sebagai teladan, pembina, sekaligus pengawas aktifitas shalat siswa. Kegiatan ini dapat pula menumbuhkan ikatan rohani antar guru, antar siswa, antara guru dan siswa.

\section{Pembinaan Keputrian}

Pembinaan keputrian dilaksanakan hari Jum'at bertepatan dengan waktu shalat Jum'at. Kegiatan diikuti oleh siswi kelas VII hingga IX secara bersama di aula sekolah. Pemateri berasal dari guru PAI dan guru mapel lain sesuai materi yang dibahas. Adapun materi pembinaan, diantaranya: masalah haid, adab terhadap orang tua dan guru, pergaulan antara laki-laki dan perempuan, dan cara berbusana. Oleh karena pembinaan ini melibatkan para siswi dan pelaksanaannya saat pelaksanaan shalat Jum'at maka di sekolah wajib ada satu guru PAI wanita, 
selain karena materi yang disampaikan tentang keputrian, hal ini dilakukan agar para siswi merasa nyaman untuk menyampaikan masalah yang dihadapinya dalam hal belajar maupun tentang haid yang rata-rata mulai dialami siswi SMP.

\section{Badan Dakwah Islam}

Badan Dakwah Islam adalah unit ekstra-sekolah di bidang agama Islam. Anggota BDI direkrut setiap awal tahun ajaran baru dan kegiatan BDI, terdiri dari: latihan kepemimpinan dasar, pelatihan khotib, latihan banjari, panitia PHBI dengan mengadakan ceramah atau lomba, dan bakti sosial ke panti asuhan, panti jompo atau yayasan anak cacat. Badan Dakwah Islam dibimbing oleh guru PAI bekerja sama dengan pemateri dari pondok pesanten Darul Ulum Jombang.

\section{Program Baca Al-Qur'an}

Program baca Al_Qur'an di SMPN 3 Malang dilaksanakan di sekolah dan di rumah. Di sekolah kegiatan tersebut masuk dalam kegiatan Imtaq, sedangkan aktifitas di rumah dipantau dengan bantuan buku catatan peningkatan imtaq yang berisi identitas siswa, lembar pantau baca Al-Qur'an, lembar pantau shalat fardhu, dan lembar setoran hapalan surat Al-Qur'an.

Untuk memantau perkembangan siswa maka dilakukan tes baca Al-Qur'an menjelang UTS di kelas pada mata pelajaran agama Islam dengan cara siswa bergantian membaca 2-3 ayat dihadapan guru PAI. Dengan adanya program ini diharapkan lulusan dari SMPN 3 Malang bisa baca Al-Qur'an. Untuk itu, sekolah harus menyiapkan tenaga pengajar profesional, sarana dan prasarana yang mendukung seperti Al-Qur'an di setiap ruang kelas dan tempat berwudhu yang proporsional.

Adapun keutamaan membaca Al-Qur'an dapat dilihat dari hadits yang dapat penulis paparkan sebagai berikut:

Artinya: "Dari Abu Umamah ra. berkata, "Aku mendengar Rasulullah saw. bersabda, Bacalah Al Qur'an karena ia akan datang pada hari kiamat untuk memberi syafaat kepada orang yang telah membaca dan mengamalkan isinya." (HR. Muslim)

Artinya: "Dari Utsman bin Affan ra. berkata bahwa Rasulullah saw. bersabda, "Sebaikbaik kalian adalah yang mempelajari Al-Qur'an dan mengajarkannya." (HR. Bukhari) ${ }^{113}$.

113 Imam An-Nawawi, Kumpulan Hadits dari Riyadhus Shalihin, (Jakarta: Asaduddin Press, 2008), hlm. 535-356. 


\section{Program Tahfidz Qur'an}

Program Tahfidz Qur'an adalah program hapalan juz 30, dilanjutkan dengan hapalan juz 1 dan juz 29. Proses setoran hapalan dilakukan disela-sela waktu pembelajaran dengan cara siswa berpasang-pasangan, satu menyetorkan hapalan dan satu lagi menyimak serta memberi tanda di buku peningkatan imtaq dibagian lembar setoran hapalan surat-surat Al-Qur'an.

Tahfidz Qur'an adalah keterampilan yang harus dimiliki siswa yang diperlukan dalam ibadah shalat sehari-hari dan mengingat keutamaan menghapal Al-Qur'an yang luar biasa. Dilansir Malang Post (23 November 2018) sebanyak 7 siswa yang telah hapal juz 30 mendapat sertifikat uji publik dari Kementerian Agama Kota Malang pada perayaan maulid Nabi Muhammad SAW tahun 1440 M di SMPN 3 Malang114.

\section{Program Amal}

Program amal dilaksanakan setiap hari Jum'at sebelum jam pelajaran pertama dengan pengumpulan uang kepada perwakilan kelas yang kemudian diserahkan kepada guru PAI. Dana yang terhimpun digunakan untuk kegiatan keagamaan, bantuan kepada siswa yang tidak mampu, dan membantu guru atau siswa yang tertimpa musibah. Pengumpulan dana amal juga dilakukan oleh para guru di SMPN 3 Malang sebesar 2.5\% dari gaji guru.

\section{Peringatan Hari Besar Islam}

Pelaksanaan Peringatan Hari Besar Islam (PHBI) di SMPN 3 Malang bertujuan untuk mendukung visi sekolah menjadi sekolah yang unggul dalam kegiatan akademis dan keagamaan. PHBI yang dilaksanakan di sekolah, diantaranya: Hari Raya Idul Adha, Tahun Baru Hijriyah, Maulid Nabi, dan Isra' Mi'raj Nabi Muhammad SAW. PHBI yang dilaksanakan di sekolah dapat mempererat tali silaturahmi antara civitas sekolah dan menjadikan SMPN 3 Malang menjadi sekolah umum agamis yang berdaya saing.

114 Malang Post, SMPN 3 Lahirkan Siswa Hafidz Alquran, https://www.malangpost.com/pendidikan/smpn-3-lahirkan-siswa-hafidz-alquran, diakses pada 11 Januari 2019. 


\section{Program Tahsin Qur'an}

Program tahsin Qur'an diikuti oleh guru SMPN 3 Malang dan dilaksanakan setiap hari Jum'at pukul 13.00-15.00 WIB. Program ini bertujuan untuk meningkatkan kegemaran guru dalam membaca Al-Qur'an, memperbaiki makhorijul huruf, dan memahamkan tentang tajwid.

Harapan dari kegiatan tahsin adalah lahirnya guru-guru yang dapat menjadi tutor dan membantu guru PAI menangani baca Al-Qur'an siswa. Dalam realitas di lapangan, tidak sedikit ditemui guru yang memiliki keterbatasan dalam baca Qur'an. Oleh karena guru adalah sosok yang digugu dan ditiru, maka guru "Muslim" wajib bisa dan harus mau terus mempelajari Al-Qur'an.

\section{Kegiatan Ramadhan}

Kegiatan Ramadhan dilaksanakan dalam bentuk pesantren kilat selama 3 hari mulai pukul 08.00-15.30 wib. Hari pertama dikhususkan untuk siswa kelas VII, hari kedua untuk siswa kelas VIII, dan hari ketiga untuk siswa kelas IX. Materi pada kegiatan ini seputar tentang adab pelajar muslim dan fiqih puasa dengan kegiatan lainnya berupa shalat dhuha, dzikir pagi, kuliah dhuha, shalat dhuhur dan shalat asar. Kegiatan ini melibatkan guru SMPN 3 Malang dan dapat melibatkan pihak ketiga, seperti: mahasiswa, santri, tokoh agama, organisasi keagamaan, atau event organizer profesional.

\section{Kesimpulan}

Kegiatan ekstrakurikuler PAI dilaksanakan dalam upaya menguatkan kompetensi siswa di bidang intrakurikuler PAI yang diajarkan melalui mata pelajaran PAI di sekolah. Kegiatan Intrakurikuler dan Ekstrakurikuler PAI harus saling bersinergi agar hasil pembelajaran PAI di sekolah dapat maksimal. Ke-10 kegiatan ekstrakurikuler PAI di SMPN 3 Malang merupakan bentuk dalam sinergitas tersebut, sehingga potensi siswa dapat ditumbuhkembangkan secara maksimal.

Tulisan ini diharapkan dapat menjadi referensi bagi pihak sekolah dalam merencanakan kegiatan ekstrakurikuler serupa di sekolah masing-masing. SMPN 3 Malang menjadi sekolah percontohan di Kota Malang melalui kegiatan keilmuan dan keagamaannya. 
Perlu diingat, pendidikan agama Islam di sekolah adalah upaya mendidik agama Islam agar siswa memiliki keimanan, pengetahuan, keterampilan, dan berakhlakul karimah sehingga menjadi manusia agamis yang berguna bagi keluarga, bangsa, dan negara. Ketiga hal tersebut yakni iman, ilmu, dan amal merupakan kesatuan utuh dalam Islam, dimana iman sebagai pondasi beragama, ilmu sebagai tangga mencapai tujuan, dan amal sebagai perwujudan jadi diri manusia.

\section{DAFTAR PUSTAKA}

A. Suradi, “Globalisasi dan Respon Pendidikan Agama Islam di Sekolah”, dalam $\begin{array}{lllll}\text { Jurnal Mudarisuna, Nol. N, No } & \text { Nol7 }\end{array}$ (DOI:http://dx.doi.org/10.22373/jm.v7i2.2364)

Direktorat Pendidikan Agama Islam, Pedoman Ekstrakurikuler PAI SMP, Jakarta: Kemenag, 2015.

Kementerian Agama RI, Panduan Umum Penyelenggaraan Kegiatan Ekstrakurikuler Pendidikan Agama Islam Sekolah Menengah Pertama, Jakarta: Direktorat Pendidikan Agama Islam, 2012.

Ketetapan No. XXVII/MPRS/1966 tentang Agama, Pendidikan dan Kebudayaan.

Majid, Abdul, Belajar dan Pembelajaran Pendidikan Agama Islam, Bandung: Remaja Rosdakarya, 2014.

Malang Post, SMPN 3 lahirkan siswa hafidz Alquran, 2018, https://www.malangpost.com/pendidikan/smpn-3-lahirkan-siswa-hafidz-alquran, diakses pada 11 Januari 2019.

Manizar, E., “Optimalisasi Pendidikan Agama Islam di Sekolah”, dalam Jurnal Tadrib, Vol. 3, No. 2, Februari 2018 (DOI: https://doi.org/10.19109/Tadrib.v3i2.1796)

Muhaimin, Pengembangan Kurikulum Pendidikan Agama Islam di Sekolah, Madrasah, dan Perguruan Tinggi, Jakarta: Rajawali Pers, 2009. 
Nawawi, Kumpulan Hadits dari Riyadhus Shalihin, Jakarta: Asaduddin Press, 2008.

Peraturan Direktur Jenderal Pendidikan Islam No. Dj.I/12A Tahun 2009 tentang Pengelolaan Kegiatan Ekstrakurikuler PAI pada Sekolah.

Peraturan Menteri Agama Nomor 16 Tahun 2010 tentang Pengelolaan Pendidikan Agama pada Sekolah.

Peraturan Pemerintah Nomor 55 Tahun 2007 tentang Pendidikan Agama dan Pendidikan Keagamaan.

Said, “Dampak Kegiatan Ekstrakurikuler Pendidikan agama Islam dalam Pembinaan Akhlak Peserta Didik di SMK Negeri 2 Raha", Tesis tidak diterbitkan, UIN Alauddin Makassar, 2012 (URL: http:/ / repositori.uin-alauddin.ac.id/5901/).

SMPN 3 Malang, http:/ / smpn3-mlg.sch.id/, diakses pada 11 Januari 2019.

Undang-Undang Dasar 1945.

Undang-Undang Nomor 20 Tahun 2003 tentang Sistem Pendidikan Nasional. 